\section{Red-Pill Robots Only, Please}

\author{
Selmer Bringsjord and Micah H. Clark
}

\begin{abstract}
Blue-pill robots are engineered to deceive (perhaps in an attempt to secure desirable ends). Red-pill robots, on the other hand, are built to do no violence to truth. While "taking the blue pill" is an option some select, this path, in the context of present and future robotics, is an exceedingly bad one by our lights, and we herein defend this position by attempting to show that the production of blue-pill robots via engineering as we know it should be avoided.
\end{abstract}

Index Terms-Robots, red pill, blue pill, deception, pleasure, truth

\section{INTRODUCTION}

As you already well know from the title, our context is the bivalent choice, famously offered in The Matrix, between the red pill and the blue pill, that is, between reality (with all its oftinjurious imperfection) and all-encompassing illusion (with its pleasurable "perfection"). This choice is offered to the hero, Neo, by Morpheus.

The Matrix, though highly entertaining for many modern viewers, is old hat, philosophically and narratologically speaking. ${ }^{1}$ Had Descartes been unable to prove that no evil genius was deceiving him about appearances (in light of the fact that an omnibenevolent and omniscient God is in control), he would have had the option of still embracing these appearances, blithely disregarding any skepticism in favor of a "happy" life. ${ }^{2}$ And Robert Nozick, who long after Descartes introduced the Matrixlike "experience machine" in his Anarchy, State, and Utopia [1], could have viewed the prospect of using the machine as preferable to reality. ${ }^{3}$ As fans of film well know, Neo too preferred the messy

1. When you're doing philosophy of AI/robotics, Philip K. Dick is usually not far from what you're thinking about, whether you know it or not; in our present case the rule holds true, since, e.g., the 1990 film Total Recall fully anticipates the red pill. And fans of sci fi will well know that some stories written before PKD anticipate at least substantive aspects of the red versus blue decision. For example, no serious autodidact in pursuit of sorting out the issues raised in our paper and in the narrative that frames it, should fail to read P.G. Wertenbaker's "The Chamber of Life," published in 1929 in Amazing Stories and now available free via Project Gutenberg http://www. gutenberg.org, after a simple search.

2. Those of the view that Descartes's reasoning fails can simply substitute "unable to apparently prove" for "unable to prove" in the sentence just given. And, of course, while Descartes lived a fortunate life by all accounts, it was far from perfect, but there is nothing to stop us from thoughtexperimentally imagining that his life was as filled with "joys" and "pleasures" as any that could be concocted in the Matrix.

3. This would have meant that Nozick was irrational since he viewed himself as giving compelling arguments against opting for the machine.

- S. Bringsjord is with the Department of Cognitive Science, the Department of Computer Science, and the Lally School of Management E Technology, Rensselaer Polytechnic Institute (RPI), Troy, NY 12180.

E-mail: selmer@rpi.edu.

- M.H. Clark is with the NASA Jet Propulsion Laboratory, California Institute of Technology, 4800 Oak Grove Drive, M/S 301-490 Pasadena, CA 91109 and the Rensselar AI \& Reasoning Laboratory, Rensselaer Polytechnic Institute.

E-mail:micah.h.clark@jpl.nasa.gov,micahhclark@alum.rpi.edu.

Manuscript received 17 Aug. 2011; accepted 20 Oct. 2011; published online 11 Nov. 2011.

Recommended for acceptance by A. Beavers.

For information on obtaining reprints of this article, please send e-mail to: taffc@computer.org, and reference IEEECS Log Number

TAFFCSI-2011-08-0056.

Digital Object Identifier no. 10.1109/T-AFFC.2011.35. but real: he opts not for blissful ignorance, but to ingest the red pill, and eventually saves the day. But he's sold out by Cypher, who sees things differently, ${ }^{4}$ and takes the blue pill.

What do these pills and the possibility of massive, pleasurable illusions have to do with robotics? Well, as you again already know from the title of the present paper, one can consider redand blue-pill robots. Not only that, but our technologized world is already experimenting with blue-pill robots-two examples from myriad ones being the ISRI-AIST robotic baby seal "PARO" [2] and the Fujitsu "Emotion Bear" robotic teddy bear [3]. These two products are marketed as therapeutic companions for the elderly and those suffering from Alzheimer's disease or dementia. For example, the Fujitsu bear is described on one official blog [4] as follows:

When [it] smiles or takes a deep breath it looks truly human. And this is exactly the idea behind it: children and lonely elderly people with psychological problems or severe chronic diseases should develop a health-promoting relationship with the furry therapeutic "assistant" just like in animal therapy with dogs or parakeets.

These products are blue-pill robots because they are intended, in part, to invite the mentally infirmed to form-with objects-the bonds of familiarity and affection usually reserved for living beings (and usually, in fact, for conscious living beings) with whom there is the possibility of worthy pleasure in reciprocation. ${ }^{5}$

Granted, this is mere dabbling in blue-pill robots; compared to true social creatures, current social robots are tinker toys. But if Bringsjord [5] is right that in keeping with such films as Blade Runner there is nearly no limit to what behaviors humanoid robots can simulate, the sky is the limit with respect to what illusions, and hence what pleasures, can be imparted by blue-pill robots. Barring some massive catastrophe, there can be little doubt that the human race will soon enough have the power to engineer thoroughly convincing blue-pill robots.

We claim that, save for perhaps some exceedingly rare exceptions (discussed below), blue-pill robots should not be built via engineering as we know it; let us denote this thesis by $\overline{\mathrm{B}-\mathrm{PRS}}$. While our thesis is entailed by a more general prohibition (to wit, that, except for rare exceptions, no blue-pill artificial agent should be built via engineering as we know it), here we focus only on robots, a subclass of such agents. ${ }^{6,7}$

\section{OUR Prediction}

We predict that if our suggested prohibition is not put in place and heeded (not only for robots, but for virtual, immersive "realities"), much if not most of human life will gradually devolve into the mad pursuit of pleasure, quite independent of truth and falsity, and consequently the human condition will be a living, throbbing, massive lie for many if not most. We simply share this prediction as a heartfelt warning; we do not defend it; do with it what you will. We share herein the argument against blue-pill robotics in large part because we believe our prediction is true, but the argument stands or falls on its own merits.

4. Cypher: "You know, I know this steak doesn't exist. I know that when I put it in my mouth, the Matrix is telling my brain that it is juicy and delicious. After nine years, you know what I realize? Ignorance is bliss."

5. These products are only mentioned for illustration, not critique. We do not claim that there is anything untoward about them specifically or about "robot therapy" generally. Indeed, their intended use probably falls within the exceptions we explicitly carve out in our discussion of caveats.

6. Some people refer to disembodied artificial agents as "robots." For us, a robot is by stipulative definition embodied. If our reasoning herein is correct with respect to robots, our prohibition straightforwardly extends to disembodied artificial agents.

7. An example of a nonrobotic, blue-pill agent is Clark's [6] "Lying Machine." 


\section{Caveats}

Our argument is intended to support the prohibition of deploying blue-pill robots in nonexotic cases. We have already made plain that prohibition of blue-pill robots may admit rare exceptions. If Smith has literally lost his mind and is wracked beyond repair with the loss of a loved one and is such that were a suitably designed blue-pill robot placed beside him, he would believe it to be his long-lost brother, perhaps he might as well be made comfortable since sanity is irretrievable; so let the blue-pill robot be so placed. ${ }^{8}$

There are other exotic cases that we happily exempt. For example, enjoyment of narrative by humans requires that these humans suspend disbelief, and in order to cause such a state of mind, writers must strive to, in a sense, deceive their audience. We have no issues with blue-pill robots being used in entertainments, ${ }^{9}$ and we figure that such use will grow increasingly frequent. For a final example of an exotic case that merits exception, consider the use of blue-pill robots in time of war, to hoodwink the enemy. ${ }^{10}$

\section{Preliminaries}

\subsection{Utilitarianism and Types of Pleasure}

We expect our readers to be generally familiar with the ethical theory known as utilitarianism. According to this doctrine, it is morally obligatory for a human agent to perform some action $a$ if and only if this action, among all alternatives, secures maximal pleasure for humans. Given this, we say that an action $a$ is utilbest for a human $h$ if the action is obligatory for $h$ by the standard defining biconditional of utilitarianism (just given in the previous sentence). ${ }^{11}$

But there is a wrinkle: While Bentham [9] proffered a version of utilitarianism according to which there is only pleasure pure and simple, unranked by type, Mill [10] provided an innovation according to which there are higher and lower pleasures. In Mill's view, ceteris paribus, the pleasure attending the reading of Plato exceeds the pleasure obtained from, say, taking a sip of fine pinot noir. ${ }^{12}$ In contemporary discussion, Benthamesque $1 D$ pleasure is generally referred to as sensory pleasure, whereas Millian multidimensional pleasure is classified as nonsensory pleasure. We will adopt contemporary usage. Moreover, to further clarify, we take sensory pleasure to centrally involve a relation between a person and sensations, as, for example, when a person experiences the sensation of tasting a fine wine. The latter form of pleasure, nonsensory, centrally involves a relation between a person and an object (e.g., another person, an animal, an abstract concept) or proposition. In addition, we draw your attention to a particular type of nonsensory pleasure that is at the core of discussion below: so-called propositional pleasure [12]. In this case, a person takes pleasure in the fact that some proposition $p$ holds. For example,

8. The essential difference between this and the MacKay ${ }_{b p r}$ case introduced below is that Smith is insane and thus cannot appreciate/take pleasure in truth. After all, if his pain were physical instead of mental, we would probably administer such things as morphine, even if doing so caused hallucinations.

9. Technically speaking, these will not be blue-pill robots: Entertainment is not a context where solemnity or sincerity are expected. By convention, an entertainer does not make solemn statements or warrant the truth of what is said; there is no expectation that the entertainer is expressing truths or personally held beliefs. Thus, there is no deception in the actor's proclamation: "Something is rotten in the state of Denmark."

10. Of course, this presumes that war (of at least certain varieties, e.g., defensive war) is itself sometimes permissible.

11. We are, of course, glossing over countless varieties of utilitarianism; the present need to achieve economy (which would be precluded by taking full account of the niceties of ethical theories) necessitates doing so. For a classic introduction to ethical theories, including utilitarianism in various forms, consult [7]. For defense of an attractive form of utilitarianism see [8].

12. All of this is economically yet crisply covered in [11]. that Gödel's first incompleteness theorem holds is something that both of us take pleasure in. Here, a triadic relation holds: one obtaining between a person, the proposition in question, and the truth of that proposition. Obviously, if the triadic relation required for propositional pleasure obtains, then the proposition involved is true.

\subsection{Blue-Pill Deception}

So far, we have only alluded to the distinction between red- and blue-pill robots. The essential difference is that blue-pill instances have present in them the "intent to deceive" [13] while red-pill instances do not. To briefly summarize this idea, one has the intent to deceive a human $h$ if one acts intending:

- $\quad$ either to contribute causally toward...

- $\quad h$ acquiring belief in a falsehood, or

- $\quad h$ continuing to believe in a falsehood, or

- $\quad h$ ceasing to believe in a truth, or

- $\quad$ preventing $h$ from acquiring belief in a truth;

- or to allow $h$ to...

- $\quad$ acquire belief in a falsehood, or

- continue believing in a falsehood, or

- cease believing in a truth, or

- continue without belief in a truth.

Now when we say that the intent to deceive is present in instances of blue-pill robots, we do not imply that the robots themselves need have intentions. They may or they may merely simulate intention. ${ }^{13}$ Furthermore, the intent to deceive may reside with creators and operators; blue-pill robots may exist as part and for the purpose of furthering other agents' intent to deceive. Recast into the context of Harnad's [15] "Total" Turing Test for robots: The intent to deceive is present for a robot competitor when either 1) the robot intends (or simulates the intent) to deceive the judge, or 2) the creator/operator of the robot intends to use said agent to deceive the judge (even if no "intent" resides in the robot itself). ${ }^{14}$

\subsection{The Hypothetical MacKay ${ }_{b p r}$}

We introduce MacKay and MacKay's blue-pill robotic doppelgänger, MacKay ${ }_{b p r}$, as fictional conveniences for our argument.

MacKay was the beautiful and brilliant son born to Lois and Henry, a young man who, at the age of 16-turning-on-17, after making it abundantly clear that he was both a Mozartian prodigy in the realm of music and a thoroughgoingly virtuous, otherregarding young fellow determined to use his prodigious musical gifts for the good of others, is killed in a car accident by a whiskeyintoxicated driver. This happening in the year 2050 means that BPR, Inc., has the technological power to deliver MacKay ${ }_{b p r}$ later on the fateful night in question in such a way that Lois and Harry (and, for that matter, everyone else who had a relationship with MacKay) are quite sure the real MacKay has come home as usual. Instead of tragedy that would have torn the entire family apart (a divorce between mother and father, a sister committing suicide in acute depression, ...), BPR, Inc., delivers an illusion that forestalls all such turbulence. ${ }^{15}$ In fact, shortly after the car

13. For a discussion of simulation versus replication, see [14].

14. This may be a good place to mention that robots (or, for that matter, agents and persons) can't cause others to believe things. All they can do is "contribute causally." Likewise, the red- or blue-pill dichotomy of The Matrix involves a choice (ditto, Adam and Eve in the Garden), and to sustain the cinematic borrowing we can echo Indiana Jones: "We must choose wisely." From this perspective, what lies, illusions, and blue-pill robots do is put a metaphorical thumb on the scales of the choice in question.

15. We leave aside complications arising from the fact that perhaps the vehicles would need to be replaced and so on. 
accident, at a family reunion in the home of Lois and Henry, MacKay's 17th birthday is joyously celebrated but the traditional happy-birthday song is smilingly sung, unwittingly, for MacKaybr, who deftly blows out the candles upon it with that same endearing, unaffected smile the family has long cherished. ${ }^{16}$

\section{The Argument}

Suppose that our thesis $\overline{\mathrm{B}-\mathrm{PRS}}$ is false; that is to say, it is in fact morally permissible to produce blue-pill robots (in nonexotic cases) via engineering as we know it, that is, B-PRs. Then, of course the design, manufacture, and deployment of MacKaybpr by such engineering is permissible. Why would this be? It can only be because such engineering produces pleasure in the relevant people. But this pleasure is obtained via the fact that truth is hidden. What view of truth and pleasure, ethically speaking, sanctions such engineering? The answer, overall, must be that as a matter of empirical fact, in nonexotic cases, it will be util-best to build blue-pill robots. But that can only be true if, in nonexotic cases, propositional pleasure doesn't outweigh other forms of nonsensory and sensory pleasure. A bit more precisely, the answer must be that, in nonexotic cases, a life (or part thereof) devoid of propositional pleasure does not have a level of aggregate pleasure less than one with it.

But then if this is true, we can say that for the engineers in question, those at BPR, Inc., it would make no difference pleasurewise if they were just "lucking out" in doing what they do. To make this clearer, suppose that the engineers at BPR, Inc., are completely and utterly mistaken about all the formal propositions they believe to be at the very heart of their engineering. To make the point vivid, we can suppose that these engineers are able to produce MacKay $_{b p r}$ and other blue-pill robots only because invisible supernatural beings in another dimension are ensuring that all the engineering works. We can assume without loss of generality that everything the BPR engineers believe and use is the perceived-by-them conclusion of an apparent deduction from selfevident axioms. But suppose that in each and every case the deduction is in fact erroneous, yet no one realizes this. Every algorithm that has supposedly been proved correct and every formula supposedly proved correct has not been so proved. Everything is a mass illusion, and the fact of the matter is that the engineers in question are idiots.

Doesn't this state-of-affairs contain less than the state-of-affairs in which the engineers do in fact have the propositional knowledge they believe they have ${ }^{17}$ This question can be personalized since we know that our readers, at least many of them, are themselves scientists and engineers. They can thus easily enough imagine themselves being either in the situation of hoodwinked BPR engineers or in the situation which they currently assume they are in, in which they enjoy propositional knowledge. So, Reader, which situation would you prefer to be in? You cannot answer that you prefer to be in the one in which propositional knowledge is secured without also admitting that the supposition which started the reasoning in our argument must be rejected. That is, such a preference entails a rejection of B-PRs. Since B-PRs must be rejected, we therefore conclude $\overline{\mathrm{B}-\mathrm{PRS}}$, on the strength of reductio and tertium non datur.

16. Bringsjord concedes that some of his other writings entail the mathematical impossibility of MacKay ${ }_{b p r}$ if this creature is a mere Turinglevel machine. The reason is that the musical ability of a Mozart exceeds the capacity of a standard Turing machine. But this can be safely left aside here because, e.g., we can simply assume that MacKay Mpr $_{\text {announces that he will }}$ do less composing in the future.

17. A full treatment of the issues at hand would require coverage of not only propositional knowledge, but second-order propositional knowledge: knowing that one knows that $p$. We leave this issue aside under current space constraints.

\section{OBJECTIONS}

\subsection{Objections against Correspondence Account}

No doubt some readers wishing to dodge our argument against blue-pill robots will object that the argument presupposes the socalled correspondence account of truth. According to this account, a proposition $p$ is true if and only if $p$ corresponds to some part of reality. Smith might, for instance, assert the proposition that the cat is on the mat while looking at the front of Bringsjord's house and spying there a large, sleek, black cat dozing on his "WELCOME" mat beside his front door. In this scenario, nearly all humans are inclined to say that Smith's assertion is true for the simple reason that there is in fact a cat on Bringsjord's (= the) mat.

In the context of the present dialectic, the objection here entails a contradiction and must therefore be immediately rejected. This is so because the very nature of the question before us (and for that matter the very nature of the question type before us: red pill versus blue pill in general) implies that there is a choice between reality and illusion-and in the case of the latter, say in the case specifically of The Matrix, a human enveloped by the illusion who believes that there is a black cat in front of him believes a proposition that isn't true for the simple reason that in reality there is no cat (but rather a machine suitably stimulating his brain). Put baldly, the fact of the matter is that those intrigued with the fundamental choice at the heart of the present investigation are all operating on the basis of the correspondence account of truth. ${ }^{18}$

\subsection{Objection from Truth-Indifferent Engineers}

A truth-indifferent engineer (or an abject cynic) can object to our argument on the grounds that engineers neither enjoy nor seek propositional pleasure. The truth-indifferent engineer might say: "I'm indifferent to truth. I don't care how it works; so long as the machine does work, I am pleased." Supposing that the engineers at BPR, Inc., are similarly disposed, is our argument overthrown? We think not.

We are both at institutions rather renowned for engineering acumen, and these associations have afforded us many opportunities to observe and engage engineers while at their practice, but we have yet to discover even one truth-indifferent engineer and fear the species does not exist. ${ }^{19}$ But putting aside what skeptics will see as little more than humorous anecdote, there are good reasons to dismiss this objection.

First, the objection is self-defeating. The statement "So long as the machine does work, I am pleased" implies propositional pleasure, namely, pleasure in the knowledge that "the machine does work." In turn, this pleasure cannot be obtained unless the machine exists and does work; illusions will not do. The truthindifferent engineer's attitude ought to have been: "So long as I experience the sensations that would have accompanied my engineering a machine that behaved as I intended it to do, I am pleased."

18. Inevitably, some readers will strive to sustain the objection by claiming that in point of fact they find the blue-vs-red choice to be, yes, profound, but they find it so because they regard this choice to be between one "reality" that is "more coherent" than another. (As cognoscenti will know, one of the main competing accounts of truth is the so-called coherence account. A nice discussion can be found in [16].) But if this move is allowed traction, the present investigation will then be held hostage by esoteric metaphysics and epistemology firmly within the province of professional philosophers content to ponder in the grip of aporia and consequently never return again to whether real robotics in the real world should or shouldn't include the manufacturing of which BPR is capable.

19. Clark, for example, has for the last 15 years been in the business of designing, constructing, and operating robots of the red-pill variety that extend humanity's reach into the Solar system. He attests that engineers as a matter of course expend considerable resources in the effort to determine that robotic space systems are predictable, reliable, and truthful prior to deployment. Such expenditures would be contrary to reason were it the case that foreknowledge of these system properties has no utility. 
Second, our argument contained the proviso "engineering as we know it"; it is far from clear that one can be both indifferent to truth and engaged in engineering as we know it. In practice and pedagogy, engineering emphasizes means and methods for the application of scientific principles, not just achieving outcomes. Indeed, the definitions of "engineering" given by encyclopedias and professional societies alike clearly require the judicious use of propositional knowledge in the production of artifacts (e.g., see [17], [18], [19]). While full-fledged "philosophy of engineering" is still emerging from infancy, ${ }^{20}$ it seems highly improbable that one can be truth-indifferent and still attend to the methodological and teleological concerns of "engineering" as a professional discipline. Thus, we conclude that "truth-indifferent engineer" is an oxymoron.

\section{CONCLUSION}

We take ourselves to have made a credible case for the engineering of red-pill robots only (save for rare exceptions). There will no doubt be other objections others will bring against our position; indeed, we fully expect a dialogue to ensue, and welcome it. However, in light of what we perceive to be ambsace between the inability of our race to engineer robust blue-pill robots and the arrival of that ability, prudence dictates that the dialogue begin rather soon.

A final word about the reach ${ }^{21}$ of what we have written: There are myriad ways in which a blue-pill robot might act or further the intent to deceive. What useful thing can we say about the vast, overall phenomenon that we have treated in the foregoing? What overarching deception unites blue-pill robots? In the context of utilitarianism, we claim that it's this: Blue-pill robots all deceive with respect to the metalevel proposition that the pleasure to be gained by accepting the fiction/lie/false object-level proposition that such robots (by existence and function) materially misrepresent is greater than the pleasure to be gained by accepting instead the truth blue-pill robots hide. In fact, an even-grander claim, we confess, is one we find quite plausible: viz., that not just robotics, but also the general march toward digital illusions that deliver pleasure, is based on the deception that the pleasure to be gained by embracing these illusions exceeds the joy of knowing the truth.

\section{REFERENCES}

[1] R. Nozick, Anarchy, State, and Utopia. Basic Books, 1974.

[2] E. Guizzo, "Paro the Robotic Seal Could Diminish Dementia," IEEE Spectrum, http://spectrum.ieee.org/robotics/home-robots/paro-therobotic-seal-cou ld-diminish-dementia, 2011.

[3] C. Cheng, "Fujitsu Talking Robot Teddy Bear: Hands-On with Video," PC Magazine, http://www.pcmag.com/article2/0,2817,2375443,00.asp, Apr. 2011.

[4] D. Klaus, "Cuddly Exterior, Clever Interior: The Robotbear," blog post, Face2Fujitsu a Web Diary for Fujitsu staff, http://blog.ts.fujitsu.com/ face2fujitsu/?p=2587, Apr. 2011.

[5] S. Bringsjord, What Robots Can and Can't Be. Kluwer, 1992.

[6] M. Clark, "Cognitive Illusions and the Lying Machine: A Blueprint for Sophistic Mendacity," PhD dissertation, Rensselaer Polytechnic Inst., Troy, N.Y., 2010.

[7] F. Feldman, Introductory Ethics. Pearson, 1978.

[8] F. Feldman, Doing the Best We Can: An Essay in Informal Deontic Logic. D. Reidel, 1986.

[9] J. Bentham, An Introduction to the Principles of Morals and Legislation. Clarendon Press, 1907.

[10] J.S. Mill, "Utilitarianism," Collected Works: Essays on Ethics, Religion and Society, J.M. Robson, ed., vol. 10, pp. 203-259, Univ. of Toronto Press, 1969.

20. For discussion of the connections between teleology, philosophy, and engineering, see the essays in [20], [21].

21 . This is as good a place as any to point out that the choice between red and blue pills can be viewed as central not only to robotics and AI, but to many other fields. For example, the choice reaches into political economy since, as Boettke [22] plausibly claims, an economy of the serf-creating type that Hayek prophetically warned us of can be considered a blue-pill-feeding one.
[11] F. Wilson, "John Stuart Mill," The Stanford Encyclopedia of Philosophy, E.N. Zalta, ed., Stanford Univ., http://plato.stanford.edu/archives/ spr2009/entries/mill/, 2009.

[12] F. Feldman, Utilitarianism, Hedonism, and Desert. Cambridge Univ. Press, 1997.

[13] R.M. Chisholm and T.D. Feehan, "The Intent to Deceive," J. Philosophy, vol. 74, no. 3, pp. 143-159, 1977.

[14] S. Bringsjord, "Review of John Searle's The Mystery of Consciousness," Minds and Machines, vol. 10, no. 3, pp. 457-459, 2000.

[15] S. Harnad, "Other Bodies, Other Minds: A Machine Incarnation of an Old Philosophical Problem," Minds and Machines, vol. 1, no. 1, pp. 43-54, 1991.

[16] J.O. Young, "The Coherence Theory of Truth," The Stanford Encyclopedia of Philosophy, E.N. Zalta, ed., Stanford Univ., http://plato.stanford.edu/ archives/fall2008/entries/truth-coherence/, Apr. 2011.

[17] Committee on the Education and Utilization of the Engineer, Commission on Eng. and Technical Systems, Nat'l Research Council, Engineering Education and Practice in the United States: Foundations of Our TechnoEconomic Future. Nat'l Academy Press, 1985.

[18] D.G. Weinert, "Appendix A: The Definition of Engineering and of Engineers in Historical Context," Eng. Education and Practice in the United States: Eng. Infrastructure Diagramming and Modeling, pp. 71-79. Nat'1 Academy Press, 1986,

[19] R.J. Smith, "Engineering," Encyclopaedia Britannica Online, Encyclopaedia Britannica, http://www.britannica.com/EBchecked/topic/187549/eng. Apr. 2011.

[20] Technical Functions: On the Use and Design of Artefacts, W. Houkes and P.E. Vermaas, eds.. Springer, 2010.

[21] Philosophy and Engineering: An Emerging Agenda, P. van de Ibo and D.E. Goldberg, eds. Springer, 2010.

[22] P. Boettke, "Human Freedom and the Red Pill," Taking the Red Pill: Science, Philosophy, and Religion in the Matrix, pp. 145-157, Benbella Books, 2003.

$\triangleright$ For more information on this or any other computing topic, please visit our Digital Library at www.computer.org/publications/dlib. 